\title{
Pengaruh Kesesuaian Penempatan Kerja, Keselamatan Kerja, Danmotivasi Kerja Terhadap Prestasi Pegawai Pada Pt. Technindo Kebun Kelapa Sawit Kabupaten Dharmasraya
}

\author{
Yeki Candra, Yosi Puspita Sari, Loly Fitri Yovani \\ Universitas Putra Indonesia YPTK Padang, Indonesia \\ E-mail : yekicandra19@gmail.com
}

\begin{abstract}
ABSTRAK
Penelitian ini bertujuan untuk mengetahui seberapa besar Pengaruh Penempatan Kerja (X1), Keselamatan Kerja (X2) dan Motivasi Kerja (X3) terhadap Prestasi Kerja (Y) sebagai variabel dependent. Dan Prestasi Kerja sebagai variabel independent, Metode pengumpulan data melalui survey dan menyebarkan kuesioner sebanyak 61 responden. Metode analisis yang digunakan adalah uji validitas dan reliabilitas, analisis korelasi, analisis regresi berganda, untuk uji hipotesis digunakan yaitu uji t dan uji $F$.

Berdasarkan hasil Uji (Uji t) Penempatan kerja, Keselamatan kerja dan motivasi kerja secara parsial berpengaruh signifikan terhadap Prestasi Kerja. Penempatan Kerja, Hasil (Uji F) Keselamatan Kerja dan Motivasi Kerja secara bersama- sama berpengaruh signifikan terhadap Prestasi Kerja. Kontribusi / sumbangan variabel Penempatan Kerja, Keselamatan Kerja dan Motivasi Kerja terhadap Prestasi Kerja sebesar 0,640 atau 64,0\% sedangkan sisanya sebesar 36,0\% ditentukan oleh variabel lain yang tidak di analisis dalam model pada penelitian ini.
\end{abstract}

Hasil penelitian ini sejalan dengan yang dilakukan Bustam (2016), Sri Rahayu (2018), Atik dwi Pratiwi (2016). Namun bertolak belakang dengan penelitian Indriani (2016), Aulia Indra (2018), Aulia Pratiwi (2018).

Kata kunci : Penempatan Kerja, Keselamatan Kerja , Motivasi kerja dan Prestasi kerja

\section{Pendahuluan}

Sumber daya manusia merupakan faktor sentral dalam pengelolaan suatu organisasi. Bagaimanapun cangggihnya teknologi yang digunakan tanpa didukung oleh manusia sebagai pelaksana kegiatan operasionalnya tidak akan mampu menghasilkan output yang sesuai dengan tingkat efisiensi yang diharapkan. Keefisienan akan tercapai jika suatu organisasi dapat memperhatikan beberapa aspek penting seperti kesesuaian penempatan kerja, dan keselamatan kerja, prestasi pegawai dari aspek-aspek lainnya. Hal ini menjadikan manajemen sumber daya manusia merupakan salah satu faktor yang sangat penting untuk pencapaian hasil kerja yang optimal

PT Technindo kebun kelapa sawit kabupaten dharmasraya mencipatakan Kelapa sawit yang unggul sehingga menarik dan memberikan produk yang berkualitas pegawai yang puas menjadi sebuah indikator yang diimpikan dalam menjalankan sebuah organisasi. Kepuasan pegawai akan memberikan dampak yang positif seperti mereka akan bekerja dengan lebih baik dan produktif, sementara karyawan yang kurang puas akan lebih sering mengabaikan pekerjaannya yang berakibat pada kerugian organisasi. Sehingga kepuasan kerja merupakan faktor yang sangat penting untuk mendap atkan hasil kerja yang optimal.Pada saat kepada konsumen. kebun kelapa sawit merupakan salah satu tanaman perkebunan di indonesia yang memiliki nilai ekonomi tinggi sehingga menjadi salah satu sumber penghasil devisa nonmigas di indonesia. Tanaman tropis ini merupakan tanaman perkebuna $\mathrm{n}$ seluas 660,32 ha di kelola pada tahun 2008, perkebunan kelapa sawit mencapai 246,82 Ha dengan produksi kelapa sawit yakni 12,665,491 ton (Direktorat jendral Perkebunan ,2015) 
Luas perkebunan kelapa sawit di indonesia terus mengalami peningkatan tiap tahunnya, dharmasraya merupakan kabupaten dengan luas perkebunan kelapa sawit terbesar ke dua di provinsi sumatera barat setelah kabupaten pasaman barat. budidaya kelapa sawit merupakan monukultur yang mensyarat pembersih awal pada lahan yang di rugikan. Secara ekologis memang pola monukultur lebih banyak merugikan karena berdampak pada hilangnya keanekaragaman pada ekosistem tersebut. Walaupum perkebunan kelapa sawit tergolong ekosistem dengan keanekaragaman yang rendah. Dalam menghadapi era persaingan ini, setiap perusahaan yang menghasilkan produk berusaha untuk mempertahankan kelangsungan usahanya masing-masing. Salah satu caranya adalah dengan mengoptimalkan kinerja dari karyawan agar kinerja perusahaan dapat terangkat lebih baik. Kinerja karyawan merupakan salah satu dimensi yang dapat digunakan untuk mengukur dan mengevaluasi kekuatan karyawan dalam bertahan serta melaksanakan tugas dan kewajibannya terhadap perusahaan. Para karyawan dituntut untuk dapat melaksanakan tugas yang dibebankan kepadanya dengan baik, yaitu dengan memaksimalkan waktu dalam bekerja, disiplin dan jujur agar dapat mencapai hasil kerja dengan kualitas dan kuantitas yang baik.

Manajemen sumber daya manusia merupakan salah satu bidang dari manajemen umum yang meliputi segi-segi perencanaan, pengorganisasian, pelaksanaan, dan pengendalian. Proses ini terdapat dalam fungsi atau bidang kepegawaian, karena sumber daya manusia dianggap sangat penting. Perannya dalam pencapaian tujuan perusahaan, maka berbagai pengalaman dan hasil penelitian dalam bidang SDM dikumpulkan secara sistematis dalam apa yang disebut manajemen sumber daya manusia.

\section{Metodologi Penelitian}

\subsection{Analisis Regresi Linear Berganda}

Alat analisis data yang digunakan dalam penelitian ini adalah analisis regresi berganda untuk membuktikan pengaruh Penempatan Kerja, Keselamatan Kerja dan Motivasi Kerja terhadap Prestasi Kerja pada PT. Technindo Kebun Kelapa Sawit Kabupaten Dharmasraya. Menurut Siregar (2015:226) secara umum regresi berganda dapat dirumuskan sebagai berikut :

$\mathrm{Y}=\mathrm{a}+\mathrm{b} 1 \mathrm{x} 1+\mathrm{b} 2 \times 2+\mathrm{b} 3 \times 3 \ldots+\mathrm{BnXn}$

\subsection{Pengujian Hipotesis}

Pengujian ini dilakukan untuk mengetahui pengaruh variabel independen terhadap variabel dependen.

\subsubsection{Uji Statistik t (Uji Signifikan Parsial)}

Uji t digunakan untuk menguji pengaruh independent variable secara parsial terhadap variable dependent. Pengujian ini dilakukan dengan ketentuan:

1. Apabila probability thitung $<0,05$, maka Ho ditolak dan Ha diterima

2. Apabila probability thitung $>0,05$, maka Ho diterima dan Ha ditolak

Berdasarkan table, menunjukkan pengaruh variable Struktur Modal (SM), Current Ratio(CR), Laba Perlembar Saham (EPS) dapat diuji sebagai berikut:

\subsubsection{Uji Statistik f}

Merupakan alat yang digunakan untuk menguji apakah variabel independen berpengaruh secara bersama-sama atau simultan terhadap variabel dependennya. Adapun kriteria pengambilan keputusan sebagai berikut: 
Jika probabilitas $<0,05$ maka hipotesis diterima

Jika probabilitas $>0,05$ maka hipotesis ditolak

\subsubsection{Koefisien Determinasi}

Koefisien determinasi $\left(R^{2}\right)$ adalah angka yang menyatakan atau digunakan untuk mengetahui kontribusi atau sumbangan yang diberikan oleh sebuah variabel bebas atau lebih terhadap variabel terikat. Nilai koefisien determinasi adalah antara nol dan satu. Nilai $\mathbf{R}_{2}$ yang kecil berarti kemampuan variabel-variabel independen dalam menjelaskan variasi variabel dependen amat terbatas. Nilai yang mendekati satu berarti variabel-variabel independen hampir memberikan semua informasi yang dibutuhkan untuk memprediksi variasivariabel dependen. Kelemahan mendasar penggunaan koefisien determinasi adalah bias terhadap jumlah variabel independen yang dimasukkan ke dalam model.

\section{Hasil dan Pembahasan}

\subsection{Analisis Regresi Linear Berganda}

Analisis dalam penelitian ini adalah analisis regresi berganda. Analisis ini digunakan untuk mengetahui pengaruh Penempatan Kerja (X1), Keselamatan Kerja(X2) danMotivasi Kerja (X3) terhadapPrestasi Kerja (Y). Adapun bentuk regresinya adalah :

$\mathrm{Y}=\mathrm{a}+\mathrm{bX} 1+\mathrm{bX} 2+\mathrm{bX} 3+\mathrm{e}$

Berikut ini tabel hasil Regresi Berganda :

Tabel 3.1

Analisis Regresi Berganda

\begin{tabular}{|c|c|c|c|c|c|}
\hline & \multicolumn{5}{|c|}{$S$} \\
\hline & $\mathrm{B}$ & $\mathrm{S}$ & B & & \\
\hline 1 & 1 & 3 & & 4 & \\
\hline (Constant) & 3 & & & & 0 \\
\hline & & 0 & 4 & 4 & 0 \\
\hline Penempata & 4 & 0 & 3 & 6 & 0 \\
\hline n.Kerja & 2 & 6 & 6 & 6 & \\
\hline
\end{tabular}

a. Dependent Variable: Prestasi.Kerja

Sumber : Data Primer Diolah, 2019

Berdasarkan tabel 4.21 diatas maka dapat dilihat persamaan regresinya yaitu: $\mathrm{Y}=13,425+$

$0,304 \mathrm{X} 1+0,250 \mathrm{X} 2+0,163 \mathrm{X} 3+\mathrm{e}$

Interprestasi berdasarkan persamaan tersebut dapat diartikan sebagai berikut :

1. Konstanta sebesar 13,425 artinya apabila Penempatan Kerja, Keselamatan Kerja dan Motivasi

Kerja tidak ada atau bernilai nol (0) maka Prestasi Kerjatetap sebesar 13,425.

2. Koefisien regresi positif (searah) sebesar 0,304artinya apabila Penempatan Kerja ditingkatkan

sebesar satu satuan bobot, dengan asumsi Keselamatan Kerja dan Motivasi Kerjadiabaikan, maka akan mengakibatkan peningkatanPrestasi Kerja sebesar 0,304 satuan bobot.

3. Koefisien regresi positif (searah) sebesar 0,250 artinya apabila Keselamatan Kerja ditingkatkan sebesar satu satuan bobot, dengan asumsi Penempatan Kerja dan Motivasi Kerja diabaikan,

maka akan mengakibatkan peningkatanPrestasi Kerja sebesar 0,250 satuan bobot. 
4. Koefisien regresi positif (searah) sebesar 0,163 artinya apabila Motivasi Kerja ditingkatkan sebesar satu satuan bobot, dengan asumsi Penempatan Kerja dan Keselamatan Kerja diabaikan, maka akan mengakibatkan peningkatanPrestasi Kerja sebesar 0,163 satuan bobot.

\subsection{Hasil Uji Hipotesis}

\subsubsection{Pengujian Secara Parsial (Uji t)}

Tabel 3.1

\section{Secara Parsial (Uji T)}

\begin{tabular}{llll}
\hline Faktor & t- & t- & Sign \\
\hline Penempatan & 3,8 & 2,00 & 0,00 \\
\hline Keselamatan & 2,6 & 2,00 & 0,01 \\
\hline Motivasi & 2,2 & 2,00 & 0,02 \\
\hline
\end{tabular}

Sumber: Data Primer diolah, 2019

Dari tabel 4.22 diatas dapat diinterprestasikan sebagai berikut :

1. Pengaruh Penempatan Kerja (X1) terhadap Prestasi Kerja(Y)

Dari tabel 4.22 diatas terlihat t-hitung 3,858dan t-tabel 2,002dimana t-hitung lebih besar dari ttabel $(3,858>2,002)$ atau tingkat signifikan lebih kecil dari dari alpha $(0,000<0,05)$ maka dapat diperoleh $\mathrm{H}_{0}$ ditolak $\mathrm{H}_{1}$ diterima. Hasil penelitian menunjukan bahwa penempatan kerjaberpengaruh positif terhadap prestasi kerja.

2. Pengaruh Keselamatan Kerja Kerja (X2) terhadap Prestasi Kerja(Y)

Dari tabel 4.22 diatas terlihat t-hitung 2,631 dan t-tabel 2,002 dimana t-hitung lebih besar dari ttabel $(2,631>2,002)$ atau tingkat signifikan lebih kecil dari dari alpha $(0,011<0,05)$ maka dapat diperoleh H0 ditolak H2diterima. Hasil penelitian menunjukan bahwa keselamatan kerjaberpengaruh positif terhadap prestasi kerja.

3. Pengaruh Motivasi Kerja (X3) terhadap Prestasi Kerja(Y)

Dari tabel 4.22 diatas terlihat t-hitung 2,237 dan t-tabel 2,002 dimana t-hitung lebih besar dari ttabel $(2,237>2,002)$ atau tingkat signifikan lebih kecil dari dari alpha $(0,029<0,05)$ maka dapat diperoleh $\mathrm{H} 0$ ditolak $\mathrm{H} 3$ diterima. Hasil penelitian menunjukan bahwa motivasi kerjaberpengaruh positif terhadap prestasi kerja

\subsubsection{Pengujian Simultan (Uji F)}

\section{Tabel 3.3}

Uji F

\begin{tabular}{|llllll|}
\hline Model & S & D & M & F & S \\
\hline 1 & 5 & 3 & 1 & 3 &, \\
Regre & 2 & 5 & 5 & & \\
ssion & 8 & 6 & & & \\
\hline
\end{tabular}

Sumber :Data Primer Diolah, 2019

a. Dependent Variable: Prestasi.Kerja

b. Predictors: (Constant), Motivasi.Kerja, Keselamatan.Kerja, Penempatan.Kerja

Dari tabel 4.23 di atas dapat dilihat pengujian ini dilakukan dengan cara membandingkan nilai

$\mathrm{F}_{\text {hitung }}$ dengan $\mathrm{F}_{\text {tabel }}$ karena nilai $\mathrm{F}_{\text {hitung }}$ lebih besar dari nilai $\mathrm{F}_{\text {tabel }} \quad(36,629>2,77)$.

Nilai F5,051dengan tingkat signifikan 0,000 lebih kecil dari 5\%. Maka diperoleh maka 
dapat diperoleh $\mathrm{H}_{0}$ ditolak Hditerima, yang berarti hal ini dilakukan secara bersama-sama antara penempatan kerja, keselamatan kerja dan motivasi kerja berpengaruh signifikan terhadap prestasi kerja.

\subsubsection{Pengujian Koefisien Determinasi $\left(\mathbf{R}^{\mathbf{2}}\right)$}

Tabel 3.4

Uji Determinsi

\begin{tabular}{|c|c|c|c|c|}
\hline $\begin{array}{l}\mathrm{M} \\
\mathrm{o}\end{array}$ & $\mathrm{R}$ & $\mathrm{R}$ & $\begin{array}{l}\mathrm{A} \\
\mathrm{dj} \\
\mathrm{u}\end{array}$ & $\begin{array}{l}\mathrm{S} \\
\mathrm{td}\end{array}$ \\
\hline $\mathrm{d}$ & & $S$ & $\begin{array}{l}\text { st } \\
\mathrm{e}\end{array}$ & $\mathrm{E}$ \\
\hline 1 & $\begin{array}{l}8 \\
1 \\
1 \\
a\end{array}$ & $\begin{array}{l}2 \\
6 \\
5 \\
8 \\
\end{array}$ & $\begin{array}{l}, 6 \\
4 \\
0\end{array}$ & $\begin{array}{r}2 \\
2 \\
4 \\
8\end{array}$ \\
\hline
\end{tabular}

Berdasarkan tabel 3.24 diatas diperoleh Adjust R Square sebesar 0,646 hal ini menunjukan bahwa sumbangan variabel penempatan kerja, keselamatan kerja dan motivasi kerja terhadap prestasi Kerja sebesar 0,640 atau 64,0\% sedangkan sisanya sebesar 36,0\% ditentukan oleh variabel lain yang tidak di analisis dalam model pada penelitian ini.

\section{Kesimpulan}

Berdasarkan kajian, hasil penelitian dan pembahasan yang telah dipaparkan sebelumnya, maka dapat ditarik kesimpulan sebagai berikut :

1. Terdapat pengaruh yang signifikan $(0,000<0,05)$ antara Penempatan Kerja terhadap Prestasi Kerja.

2. Terdapat pengaruh yang signifikan $(0,011<0,05)$ antara Keselamatan Kerja terhadap PrestasiKerja

3. Terdapat pengaruh yang signifikan $(0,029<0,05)$ antara Motivasi Kerja terhadap Prestasi Kerja.

4. Terdapat pengaruh yang signifikan $(0,000<0,05)$ antara Penempatan Kerja, Keselamtan Kerja dan Motivasi Kerja secara bersama-sama terhadap Prestasi Kerj.

5. Kontribusi variabel penempatan kerja, keselamatan kerja dan motivasi kerja terhadap prestasi kerja sebesar 0,640 atau $64,0 \%$ sedangkan sisanya sebesar $36,0 \%$ ditentukan oleh variabel lain yang tidak dianalisis dalam model pada penelitian ini.

\section{Referensi}

[1] Afifuddin. 2014. Manajemen Personalia, cetakan ke 1. Bandung: CV Pustaka Setia.

[2] Atik Dwi Pratiwi, Amin Wahyudi 2016 Pengaruh Hubungan Kerja, Motivasi Kerja, Dan Lingkungan Kerja Karyawan

[3] Aulia Pratiwi, Alini Gilang, SH., MM. 2015 Pengaruh Kesesuaian Penempatan Pegawai Terhadap Prestasi Kerja Pegawai Pada Build Better Comunication-English Training Specialaist (BBC- ETS) Cabang Rawamangun Jakarta,

[4] Aulia Indra 2018 Pengaruh Keselamatan Dan Kesehatan Kerja (k3) terhadap Prestasi KerjaKaryawan Pada PT. Pertamina (Persero) Medan 
[5] Bustam, Nurlaely Razak, Andi Rahmat Hidayat, Natasya Ayudia, Hesti Pratiwi

[6] Fahmi, Irham. 2014. Manajemen Resiko teori, Kasus, dan Solusi. Cetakan keempat. Bandung: Alfabeta.

[7] Hamali, Arif Yusuf. 2016. Pemahaman Manajemen Sumber Daya Manusia, cetakan pertama. Jakarta :CAPS (Center for Academic Publishing Service).

[8] Hartatik, Indah Puji. 2014. Buku Praktis Mengembangkan SDM, cetakan pertama. Yogjakarta: Laksana.

[9] Hasibuan S. P Malayu. 2012. Manajemen Sumber Daya Manusia, cetakan ke enam belas Jakarta:

PT.Bumi Aksara.

[10] Hendro Pongantung, Rita N. Taroreh 2018 Pengaruh Pemberian Insentif Dan Disiplin Kerja Terhadap Prestasi Kerja Di PT. Hasjrat Abadi Manado Branch

[11] Indriani W. Matatantu, Bernhard Tewal, Jantje, Sepang 2016 Analisis Kesehatan Dan Keselamatan Kerja (K3), Evaluasi Kinerja, Dan Pemabagian Kerja Serta Pengaruhnya

Terhadap Prestasi Kerja Karyawan (Study kasus Pada PT. PLN (Persero) Area Manado

[12] Mulyawan, Setia. 2015. Manajemen Resiko, cetakan pertama. Bandung: CV Pustaka Setia.Sinambola, Lijan Poltak. 2017, Manajemen Sumber Daya Manusia. Cetakan Kedua. Jakarta: PT Bumi Aksara.

[13] Riska arum Wijayanti, Retno Dewi Pramodia 2018 Pengaruh Disiplin Kerja Dan Motivasi Kerja Perangkat Desa Di Kecamatan Getesan Kabupaten Semarang

[14] Sri Rahayu,SE.,MM 2018 Pengaruh Motivasi Dan Disiplin Terhadap Prestasi Kerja Karyawan Di PT.Langkat Nusantara Kepong KabupatenLangkat

[15] Sutrisno, Edy. 2009. ManajemenSumberDayaManusia, edisipertama. Jakarta :Prenada Group.

[16] Sugiyono. 2014. Metode Penelitian Kuantitatif, Kualitatif dan R \& D. Cetakan 14. Bandung: Alfabeta. Uha, Ismail Nawawi. 2013. Budaya Organisasi Kepemimpinan \& Kinerja, Edisi Pertama.

Depok:Kencana.

[17] Syahrlianti, MursalimUmar, Gani Arianti 2019 Pengaruh Kemampuan, Motivasi Instrinsik Terhadap Prestasi Kerja Pegawai 